\title{
Relative Importance of Food in Tourism: A Study on Domestic Tourists in Bangladesh
}

\author{
Kamrul Hassan ${ }^{1 *}$, Tasnim Mosharaf ${ }^{2}$ and Farzana Afroz $^{3}$ \\ ${ }^{1}$ Associate Professor, Department of Tourism and Hospitality Management, University of Dhaka, Bangladesh \\ "Email of the corresponding author: mkhassan@du.ac.bd \\ ${ }^{2}$ MBA Student, Department of Tourism and Hospitality Management, University of Dhaka, Bangladesh \\ ${ }^{3}$ Assistant Professor, Department of Statistics, University of Dhaka, Bangladesh
}

\begin{abstract}
The phenomenon of food tourism becomes a growing interest among many researchers as food is an important component of the travel and tourism industry. Demographic characteristics of tourists of food tourism, food preference, tourists' perceptions regarding food, aesthetic and authenticity of food, potentials of food tourism business are widely covered by the researchers' community in different contexts. To address the contextual gap, this research aims to reveal the relative roles of food in tourism along with the demographic nature of tourists who are concern to the local food of domestic tourism destinations in Bangladesh. Quantitative techniques including univariate analysis, bivariate analysis, and logistic regression have been utilized to explore the research aim. This research has found that food has a strong influence in traveling behavior of the domestic tourists in Bangladesh. In relation to demographic characteristics, male and higher educated tourists have exhibited more concern regarding local food of tourist destination. Besides, this research has found that food is one of the considerable purposes of tourism, local food is more important to the frequent travelers, and tourists consider characteristics such as healthiness, famous qualities and restaurant environment before consuming local food.
\end{abstract}

Keywords: Food tourism, demographic characteristics, univariate and bivariate analysis, logistic regression

DOI: $10.7176 / \mathrm{JTHS} / 51-06$

Publication date:November $30^{\text {th }} 2020$

\section{Introduction}

Food has always been an unabated part of the travelling wisdom and the way people perceive and experience it these days is altogether different from how it used to be (Morris, 2015). Food tourism means enjoying new foods of destinations and exploring new culinary cultures and tastes (Long, 2013). Food has been used as a means of tourism attraction by many destinations as a triumphant marketing strategy (Lin et al., 2011). It is a significant part of the culture of a region which helps to express elusive heritage (Updhyay \& Sharma, 2014). Food tourism is like participating and experiencing in the food way of other people that include consumption, presentation and preparation of food items (Long, 2013). Food tasting or experiencing the attributes of a professional food production region are the core inspiring features for travel visitation to primary and secondary food producer, food festivals, restaurant and specific location (Hall et al., 2004; Mitchell et al., 2004). Food can be considered as both a product and a symbol through food related promotional activities such as food festivals and exhibitions of agricultural product which can offer an evocative experience for tourists (Long, 2013).

The connection between food and tourism is a vital issue that cannot be ignored (Ab Karim \& Chi, 2010). Food can positively present a destination as a basic need for tourist and also as a cultural element (Jones et al., 2003). Many researchers have shown that travelers' decision while choosing their vacation destination has impacted by cuisine (Ab Karim \& Chi, 2010; Boniface, 2017; Y. H. Kim et al., 2010; McKercher et al., 2008). The Italian tourism industry has boosted by Italian cuisine and wine (Hjalager \& Corigliano, 2000). Similarly, the image of France as tourism destination has always been related to its foods and drinks (Frochot, 2003). The most significant factor that determined the travelers' satisfaction of Turkey is its food and the major cause why people revisited there is its gastronomy (RIMMINGTON \& YÜKSEL, 1998). The success of Italian cuisine is mainly imputed to the incorporation of its cuisine into its national pride and Italian food reflects its culture and lifestyle of people which play an important role to attract more tourists (Ab Karim \& Chi, 2010). The growing number of restaurant offering varieties of cuisines is the main reason for the increasing number of tourist arrivals of Hong Kong ( $\mathrm{Ab}$ Karim \& Chi, 2010). Nowadays, the most frequent leisure activities are dining in a restaurant which is a source of a memorable experience for tourists (Mitchell et al., 2004). Restaurants play an essential role in food tourism and 
considered as a gateway to food tourism (Updhyay \& Sharma, 2014).

The availability and assortment of food can play an essential role in managing and developing a destination image as food helps to protect the identity and culture (Quan \& Wang, 2003). To represent a destination's “cultural experience, status, cultural identity and communication" it can use its food (Frochot, 2003, p.82). Food can be a remarkable element of a tour which can provide memorable experience to tourists and it can represent a destination's image and distinctiveness (Ab Karim \& Chi, 2010). Food can show an unforgettable experience and pleasure to tourists (Quan \& Wang, 2003). In today's marketplace food tourism is steadily growing and highly demanded (Ab Karim \& Chi, 2010). A destination's attributes along with its local food play an essential role to add a range of attractions and overall tourist satisfaction (Symons, 1999). That is why a lot of marketing companies utilize food as a means of 'cultural artefact' (Barthes, 2012). Impression of and satisfaction with a tourism destination, in general, is seemed to be significantly contributed by food, that has been understood by and confirmed with the exhibited connection between food and tourism (Ab Karim \& Chi, 2010).

Although Bangladesh is blessed with various delicacies, how much priority domestic tourists give to the food when selecting their travel destination is still unknown. It is necessary to know the domestic tourists' views regarding Bangladeshi food as food can be a powerful attraction for selecting a destination. Through various foods, more potential tourist can be attracted and it will help to motivate the tourists to revisit a destination. Besides, it will also help the Destination Management Organization (DMO) to develop effective marketing strategies to uphold and uplift the improvement of food tourism. This study aims to generate an understanding of the relative importance of food in tourism in the context of domestic tourists in Bangladesh. Specifically, it will explore to find out the importance of food as a motivator for selecting a destination. In particular, it fills the gap by providing a thorough exploration of tourists' views regarding the importance of food before selecting a tourist's destination.

\section{Literature review}

Nowadays, people are more attracted to experience new and alternative cuisine which inspire them to travel to emerging places especially to enjoy exotic food in its actual habitat and see how it is prepared on the spot (Morris, 2015). People who travel for tasting food also known as gastronomic tourist, are willing to travel to other places to taste and experience local aesthetic and authentic cuisine of the destination (Pullphothong \& Sopha, 2019). Food tourism makes use of the senses of taste, smell, touch and vision, offers a profound and integrated level of experience whereas tourism related to sightseeing provides a fractional involvement (Long, 2013). People somehow get the opportunities to perceive the local food which differed from their usual life, when they visit to another place (Pullphothong \& Sopha, 2019). Food tourism engages one's physical being as both observer and participant (Long, 2013). Food tourism or travel for tourism has turned out to be a trend in many countries and countries such as France, Italy and Thailand which are popular with their cuisine have been popular because of the food tourism (Ab Karim \& Chi, 2010).

Food tourism, culinary tourism or gastronomy tourism is one kind of tourism activity related to food and these terms have the similar meaning which refers to people travel for the purpose of finding food to a specific destination (Ab Karim \& Chi, 2010). 'Culinary' is an adjective form of cuisine, consists of the social context of acquiring, preparing and consuming food as well as the ways of and approaches to food preparation (Updhyay \& Sharma, 2014). Based on the level of interest and number of tourists, the food tourism activities can be categorized into three areas: a) gourmet or gastronomic tourism, b) culinary tourism, and c) urban and rural tourism (Hall et al., 2004). In addition to the core connotation of these three categories, the key discriminant between these three categories is the level of interest in food of tourist (Updhyay \& Sharma, 2014). In gourmet tourism, the activities of tourists are highly related to food such as visiting luxurious restaurants that has attractive offers; and in culinary tourism, specially, a moderate type of interest is showed revolving food and food is treated as an essential part but not the everything of the tourism (Updhyay \& Sharma, 2014).

Food is a considerable tourism attraction for many destinations where it is utilized to strengthen their marketing strategy (Lin et al., 2011). By positioning food as a premier tourism product and by taking advantage of it a region 
can be benefited highly as the value of the destination increase (Ab Karim \& Chi, 2010). Many tourists like to taste regional cuisine of the destinations they visit (Lin et al., 2011). Along with the restaurant environment, local food outlets, F\&B shops, food production farms attract tourists to visit (Hall et al., 2004). To promote a destination along with its uniqueness and to choose the destination, local food can be very essential determinant (Chen $\&$ Huang, 2016; Kivela \& Crotts, 2006; Okumus et al., 2013). For reflecting and expressing the distinctiveness of a particular destination, food can serve as a powerful vehicle (Lin et al., 2011). Three influential factors including ambience and standard of the place of dine out, accessibility to the food location, and food and service quality along with stuffs' empathy are important while selecting a food tourism destination (Jacobsen \& Haukeland, 2002). Food as an important feature which is used by potential tourist in creating image of tourism destination and it also influences consumer satisfaction (Grbac \& Milohanović, 2008). For promotional activities and local development, service providers, destinations, countries or regions can utilize local food as a tourism resource (Björk \& Kauppinen-Räisänen, 2016).

The main concern of food consumption studies is to understand the factors affecting variant food related attitudes such as taste, liking, selection, and ingestion (Mak et al., 2012b). Food preference can be influenced by various factors like food availability, its perceived health value, benefit and monetary considerations but these factors may not influence food preference (Logue, 1991). Tourists' previous outlook towards food and eating might switch and a different set of dictation might impact their performances and preference of food in the new and unknown ambience (Mak et al., 2012b). In the context of tourism, there are some effective factors which can affect food consumption and it can be categorized into three main classes such as the tourists, the food and the environment (Randall \& Sanjur, 1981). Socio-cultural, psychological and physiological aspects can affect directly or indirectly on food consumption behavior of the tourist (Mak et al., 2012b). In the destination, food presents various factor like impressible quality, content of the food and preparing method (Chang et al., 2010; Cohen \& Avieli, 2004; Mak et al., 2012b). Gastronomic image, marketing communication, service encounter and servicescape can be influenced by the environment of the destination (Chang et al., 2011; Fox, 2007; Mak et al., 2012b). In the Figure 1 these factors are shown elaborately.

Figure 1: Factors affecting food consumption in tourism

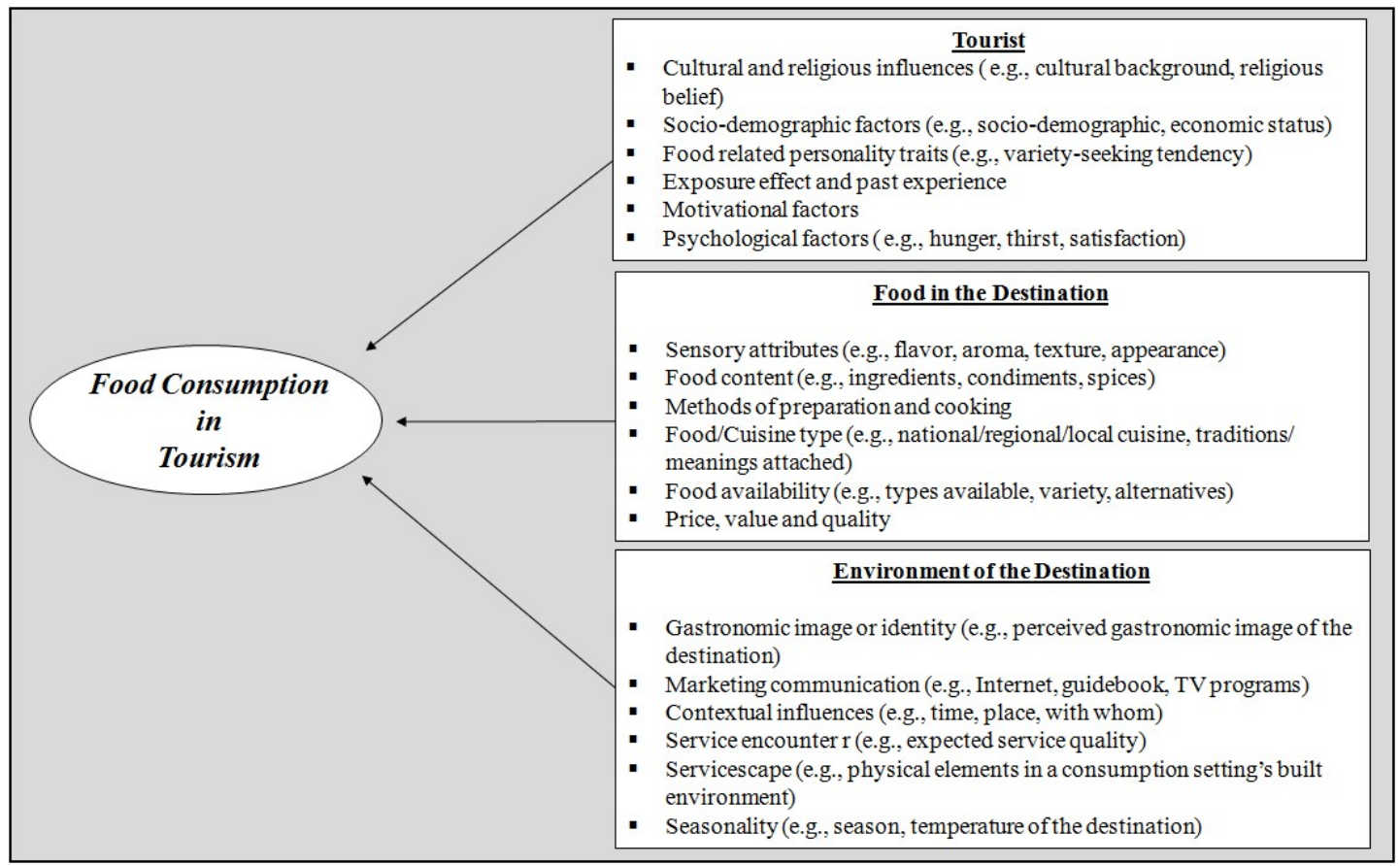

Source: Mak et al. (2012) reproduce from Randall \& Sanjur (1981) 
One of the core factors influencing tourists' food consumption behavior is culture and religion which have been widely recognized (Mak et al., 2012b). The acceptable foods and food qualities are determined by the culture of a particular group of people in terms of their sensory characteristics (Prescott et al., 2002). Another crucial factor which can influence food choice and consumption is the religious background (Khan \& Hackler, 1981; Mak et al., $2012 b$ ). For example, because of religious belief, some kinds of foods are forbidden in Islam or Judaism, specific food preparation manners are commanded such as halal and kosher or, fasting is observed in the month of Ramadan (Mak et al., 2012b; Packard \& McWILLIAMS, 1993). Food-related personality traits are also very effective psychological factors which can affect tourist food consumption (Mak et al., 2012b). Tourist food consumption can also be affected by the exposure effect and past experience as it can enhance the awareness of particular cuisine in a destination and consequently improve tourist inclination towards it (Mak et al., 2012b). In order to develop positive attitude towards food as well as restaurant environment, it must be authentic so that this authenticity leads tourist to revisit in a particular destination and repurchase from a particular restaurant (Jang et al., 2012; Özdemir \& Seyitoğlu, 2017). Besides, the healthiness of local food plays a role as an internal motivator which can motivate tourists to visit a destination (Chen \& Huang, 2016; Pearson et al., 2011).

Social and demographic characteristics of tourists can affect the food consumption behavior, which is suggested by tourism literature (Mak et al., 2012b). To describe food consumption behavior, many food consumption researchers demonstrate that socio-demographic characteristics (e.g. social class, age, gender, marital status, education level, occupation and income) are very essential variables among many contexts (Furst et al., 1996; Khan \& Hackler, 1981; Randall \& Sanjur, 1981). In accounting for variations in food preferences, age, gender and social status are significant (Mak et al., 2012b). For example, compared to younger person, older people tend to show different food choices due to loss of taste buds and sensitivity (Khan \& Hackler, 1981). A range of food explorations are negatively correlated with tourists' age (Tse \& Crotts, 2005). This indicates that older tourists may enjoy a confined a number of foods items obtainable in a destination (Mak et al., 2012b). Tourists' local food consumption also depends on gender, age and education (Y. G. Kim et al., 2009). According to (Chen \& Huang, 2016; Ignatov \& Smith, 2006), females exhibit more interested than male to involve in food consumption activities.

Food and beverage consumption in a tourist destination plays a role of central point for most people in their tourists experiences (Beer, 2008). Tourists also stay in a destination for the purpose of consuming delicious food in a friendly and nice environment (Hjalager \& Corigliano, 2000). Food has a considerable role to represent a destination and it is an attractive resource in tourism catalogs which helps to increase the income of the destination facilities connecting with the regional activities (Mak et al., 2012b). It has been widely researched that food consumption opportunity is a motivator to travel in a tourist destination (Updhyay \& Sharma, 2013). Most of the tourists' motivation to travel is captured by the consumption of food that includes leisure activities, thrill and adventure, escape from routine line, learning new things, social class and way of life (Corigliano, 2003). Food plays an essential role as a destination effective promotional and positioning tool (Hjalager \& Richards, 2003). It is an important vehicle for tourism as it has the power to define tourist destination (Long, 2013). Due to having unique cuisine, a village, a township, a city, even a whole country can be popular worldwide (Cohen \& Avieli, 2004).

\section{Methodology and methods}

In order to obtain the objective, a quantitative technique has been adopted in this research project. The study has utilized questionnaire as survey instrument to collect information from the respondents. The sample of the study has been collected by following non-probability convenience sampling method. The questionnaire includes a range of questions related to social and demographic characteristics of respondents including gender, education level, age, occupation, marital status and income level as well as questions to investigate domestic tourist interest to visit different local destinations including the reasons and the influence of food on their motivation to visit different domestic destinations in Bangladesh. The questionnaire was prepared in English. The questionnaire structure included some question identifying domestic tourists travel characteristics in relation to food tourism. Five-point Likert Scale have been used to collect information from the respondents of the study. Before applying the data collection instrument, the questions were pre-tested by the authors of the current research. 
The data was collected through both online and offline survey. During online survey, Google Form has been used to reach the participant. The offline survey has been conducted through on-site interviews. Total of 250 responses were collected. Among these 250 responses, 180 were obtained through online and the remaining 70 responses were collected through on-site face-to-face interview. After collecting the data, incomplete responses were removed and 200 valid responses were used in subsequent analysis. This study used survey confidentiality and anonymity. The collected data were coded manually and analyzed by using the Statistical Package for Social Science (SPSS) version 23.0 data analysis software. In order to address the research objective several statistical techniques such as univariate analysis, bivariate analysis, descriptive statistics and logistic regression have been applied.

The data we have collected is cross sectional. This research has addressed whether food is a potential motivator for traveling. For this purpose, the variable 'food as a motivator' was recorded to a dichotomous variable as follows: Food as a motivator to travel, $y_{i}=\left\{\begin{array}{l}0, \text { if no } \\ 1, \text { if yes }\end{array}\right.$

Further this variable was treated as a dependent variable and a bivariate analysis is done to check the association with this dependent variable with other six selected explanatory variables gender, age, marital status, occupation, education and income. To study in convenient way we also recoded this explanatory variables. The recoded categories and percentage distribution of the selected explanatory variables are displayed in Table 1. In this research, logistic regression model has been applied to to address which demographic variables better influence the dependent variable. The logistic regression model under this set up can be written as -

$$
\operatorname{Pr}\left(y_{i}=1 \mid x_{i}\right)=\frac{\exp \left(x_{i}^{T} \beta\right)}{1+\exp \left(x_{i}^{T} \beta\right)}, i=1,2, \ldots, 200
$$

where, $y_{i}$ is the response of the $i^{\text {th }}$ individual and $x_{i}=\left(x_{i 1}, \ldots, x_{i 6}\right)$ is the associated covariates vector. Maximum likelihood estimation approach using Newton-Rapson iteration procedure has been applied to estimate the model parameter $\beta$.

\section{Research findings}

The categories and percentage distribution of different variables developed by univariate analysis are given in Table 1. In case of the variable gender, the number of female participants is 78 , which is $39 \%$ of the total participants. The number of male participants is 122 , which is $61 \%$ of the total population. For the variable age, it is seen that among the participants $47 \%$ are below 30 years, $27 \%$ are between 30 to 40 years and $26 \%$ are above 40 years. A large number of (54\%) participants are unmarried. It is observed that the largest part of the participants is government or autonomous job holder. A good number of participants (43\%) are graduate and postgraduate $45 \%$. Half of the participants earn more than 30,000 taka per month while the other half earn below 30,000 per month. 
Table 1: Demographic profile of the sampled participants

\begin{tabular}{cccc}
\hline $\begin{array}{c}\text { Explanatory } \\
\text { Variables }\end{array}$ & Category & Number & Percentage \\
\hline Gender & Female & 78 & $39 \%$ \\
& Male & 122 & $61 \%$ \\
Age & $<30$ & & $47 \%$ \\
& $30-40$ & 94 & $27 \%$ \\
& $>40$ & 54 & $26 \%$ \\
Marital status & 52 & $54 \%$ \\
& Unmarried & 108 & $46 \%$ \\
Occupation & & 92 & \\
& Married & & $28 \%$ \\
& Student & 56 & $31 \%$ \\
& Govt. and Autonomous & 62 & $22 \%$ \\
Education & Othere & 44 & $19 \%$ \\
& & 38 & $12 \%$ \\
& Below graduate & 24 & $43 \%$ \\
Income & Graduate-level & 86 & $45 \%$ \\
& Postgraduate & 90 & $50 \%$ \\
& & & $50 \%$ \\
\hline
\end{tabular}

This study has observed the association between different variables and the food motivator variable by bivariate analysis. The results are presented in Table 2. Chi-square test is performed for testing the significance of the association. From the table, it can be said that food plays as a motivator of travelling for most of the participants of different categories. Male participants are more likely to consider food as a motivator compared to females for their travelling. Again, taking food as a motivator is the highest for the people aged more than 40 years and lowest for the people aged less than 30 years. Married participants are less likely to consider food as a motivator compared to the unmarried participants. Student, private, government and autonomous employees are less likely to consider food as a motivator compared to the other occupation group. From the chi-square test result, it is found that only two variables Gender and Education have a significant effect in considering food as a motivator of travelling. 
Table 2: Examining the association between food as a motivator and selected variables

\begin{tabular}{|c|c|c|c|c|}
\hline \multirow[t]{2}{*}{$\begin{array}{l}\text { Explanatory } \\
\text { Variables }\end{array}$} & \multirow[t]{2}{*}{ Category } & \multicolumn{2}{|c|}{$\begin{array}{c}\text { Food as a motivator of } \\
\text { travelling }\end{array}$} & \multirow[t]{2}{*}{ Total } \\
\hline & & Yes & No & \\
\hline${ }^{*}$ Gender & $\begin{array}{c}\text { Female } \\
\text { Male }\end{array}$ & $\begin{array}{c}60(76.9 \%) \\
109(89.3 \%)\end{array}$ & $\begin{array}{l}18(23.1 \%) \\
13(10.7 \%)\end{array}$ & $\begin{array}{c}78 \\
122\end{array}$ \\
\hline Age & $\begin{array}{c}<30 \\
30-40 \\
>40\end{array}$ & $\begin{array}{l}77(81.9 \%) \\
45(83.3 \%) \\
47(90.4 \%)\end{array}$ & $\begin{array}{c}17(18.1 \%) \\
9(16.7 \%) \\
5(9.6 \%)\end{array}$ & $\begin{array}{l}94 \\
54 \\
52\end{array}$ \\
\hline Marital status & $\begin{array}{l}\text { Unmarried } \\
\text { Married }\end{array}$ & $\begin{array}{l}89(82.4 \% \\
80(87.0 \%\end{array}$ & $\begin{array}{l}19(17.6 \%) \\
12(13.0 \%)\end{array}$ & $\begin{array}{c}108 \\
92\end{array}$ \\
\hline Occupation & $\begin{array}{c}\text { Student } \\
\text { Govt. and Autonomous } \\
\text { Private } \\
\text { other }\end{array}$ & $\begin{array}{l}47(83.9 \%) \\
54(87.1 \%) \\
33(75.0 \%) \\
35(92.1 \%)\end{array}$ & $\begin{array}{c}9(16.1 \%) \\
8(12.9 \%) \\
11(25.0 \%) \\
3(7.9 \%)\end{array}$ & $\begin{array}{l}56 \\
62 \\
44 \\
38\end{array}$ \\
\hline${ }^{* *}$ Education & $\begin{array}{l}\text { Below graduate } \\
\text { Graduate } \\
\text { Post Graduate }\end{array}$ & $\begin{array}{l}23(95.8 \%) \\
65(75.6 \%) \\
81(90.0 \%)\end{array}$ & $\begin{array}{c}1(4.2 \%) \\
21(24.4 \%) \\
9(10.0 \%)\end{array}$ & $\begin{array}{l}24 \\
86 \\
90\end{array}$ \\
\hline Income & $\begin{array}{l}<30,000 \\
>30,000\end{array}$ & $\begin{array}{l}86(86.0 \%) \\
83(83.0 \%)\end{array}$ & $\begin{array}{l}14(14.0 \%) \\
17(17.0 \%)\end{array}$ & $\begin{array}{l}100 \\
100\end{array}$ \\
\hline
\end{tabular}

Bivariate analysis between two variables does not always entail a considerable cause and effect relationship between the variables of interest. However, logistic regression has been applied to determine which factors best explain and predict consideration of food as a motivator of travelling. This study has fitted a logistic regression model by using maximum likelihood estimation. The estimates of logistic regression model parameters along with their Wald test results are given in Table 3. In the logistic regression model, the analysis has included only those variables which have been found to be significant in bivariate analysis. Thus the variables Gender and Education have been included in the logistic regression model. Now from Table 2 is can be observed that the odds of considering food as a motivator of travelling is 3.169 times higher for males than females. This result is highly significant $(\mathrm{p}<0.01)$. This may happen because males are more adventurous and explore lover naturally compared to female. Again, the odds of considering food as a travelling motivator for postgraduates is 0.283 times lesser than undergraduates. This is apparent because the undergrads are young people who are more energetic and enthusiastic of exploring the taste of new food. 
Table 3: Estimates of logistic regression model parameters

\begin{tabular}{cccccc}
\hline Variable & $\widehat{\boldsymbol{\beta}}$ & S.E. & Wald test & p-value & $\operatorname{Exp}(\widehat{\boldsymbol{\beta}})$ \\
\hline Gender (Ref=Female) & $1.153^{* *}$ & 0.421 & 7.505 & 0.006 & 3.169 \\
Male & & & & & \\
$\quad 0.925$ & 1.008 & 0.723 & 0.395 & 2.522 \\
$\quad-1.264^{* *}$ & 0.450 & 7.878 & 0.005 & 0.283 \\
$\begin{array}{c}\text { Education (Ref=under graduate) } \\
\quad \text { Graduate } \\
\text { Postgraduate }\end{array}$ & & & & & \\
$\quad$
\end{tabular}

In relation to the major purpose of domestic tourism (i.e. sightseeing, visiting friends and relatives, and religion), local food has been identified as an important motivator to travel a national destination by the respondents of this research (Figure 2). The result found by the survey exhibits that sightseeing scored maximum mean value (4.55) and traveling for religion scored minimum mean value (3.58) among the major categories of travel purpose in the context of Bangladesh. Difference of mean value between these two categories is less than 1 as religion is one of the core purposes of tourism. Visiting friends and relatives is another major reason to travel domestically as a large number of people travel to their village houses during festivals. As a motivator to travel, in comparison to these three purposes (see Figure 2), local food scored a quite considerable mean value (4.05). This result portrays the relative importance of local food in tourism that is widely ignored by previous research works.

Figure 2: Relative importance of local food among other major purposes of tourism

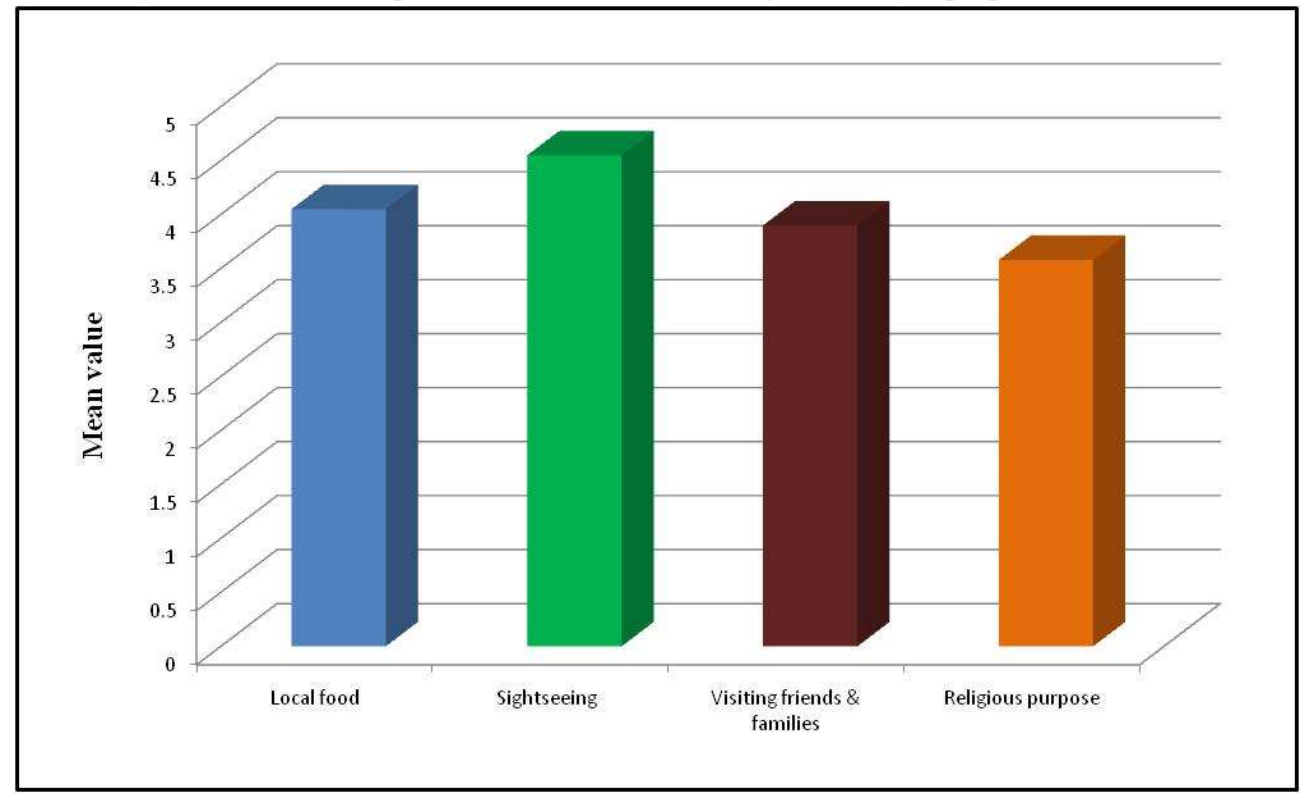

This research indicates that food is an important motivator to all types of tourists - classified based on the frequency of travel (Figure 3). In order to address the objective of this study, tourists are categorized into three core types: irregular traveler (no traveling or one traveling in a year), frequent traveler (two to four tours in a year), and most frequent traveler (five or more travel in a year). Note that the 'travel' includes at least one overnight stay in a domestic destination. Approximately $85 \%$ of respondents either agree or strongly agree for that local food attracts them and a reason for traveling a domestic destination. Almost every place in Bangladesh there is one or more famous local food that tourists like to taste. Only $4 \%$ of the respondents from most frequent travelers answered local foods do not affect their travel decision. This result depicts that tourism manager of destinations might uplift 
the value by emphasizing on foods.

Figure 3: Importance of local food to different categories of tourists

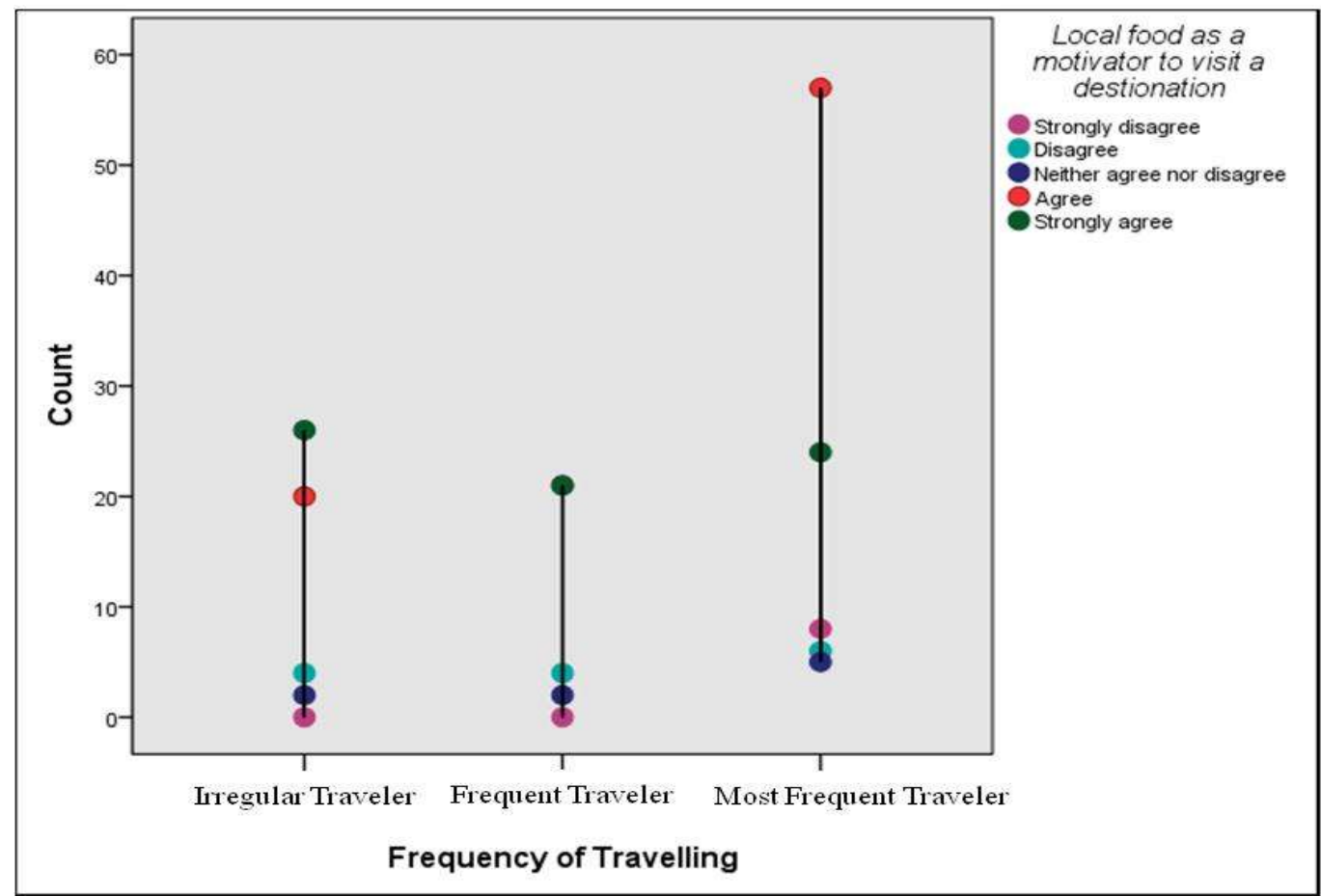

When selecting a local food by tourists in a destination, they often consider a range of criteria presented in Figure 4. The six criteria of local food choice those have been identified by this study are: uniqueness, authenticity, healthy, famous, restaurant environment, and food aesthetic. approximately $35 \%$ of the respondents consider whether the food is healthy on not. If there is any chance of being unhealthy, this segment of tourists never try the food. More than $20 \%$ of the survey participants consider tasting the famous foods of the locality in the destination. Restaurant environment is also an important criterion of taking local food to about $15 \%$ of the respondents - the others might not care about the eating environment seriously. Nearly $10 \%$ respondents informed that unique food, authenticity of food production and presentation, and aesthetic value of the foods influence their behavior on local food consumption in a destination. 
Figure 4: Criteria considered by tourists while local food selection

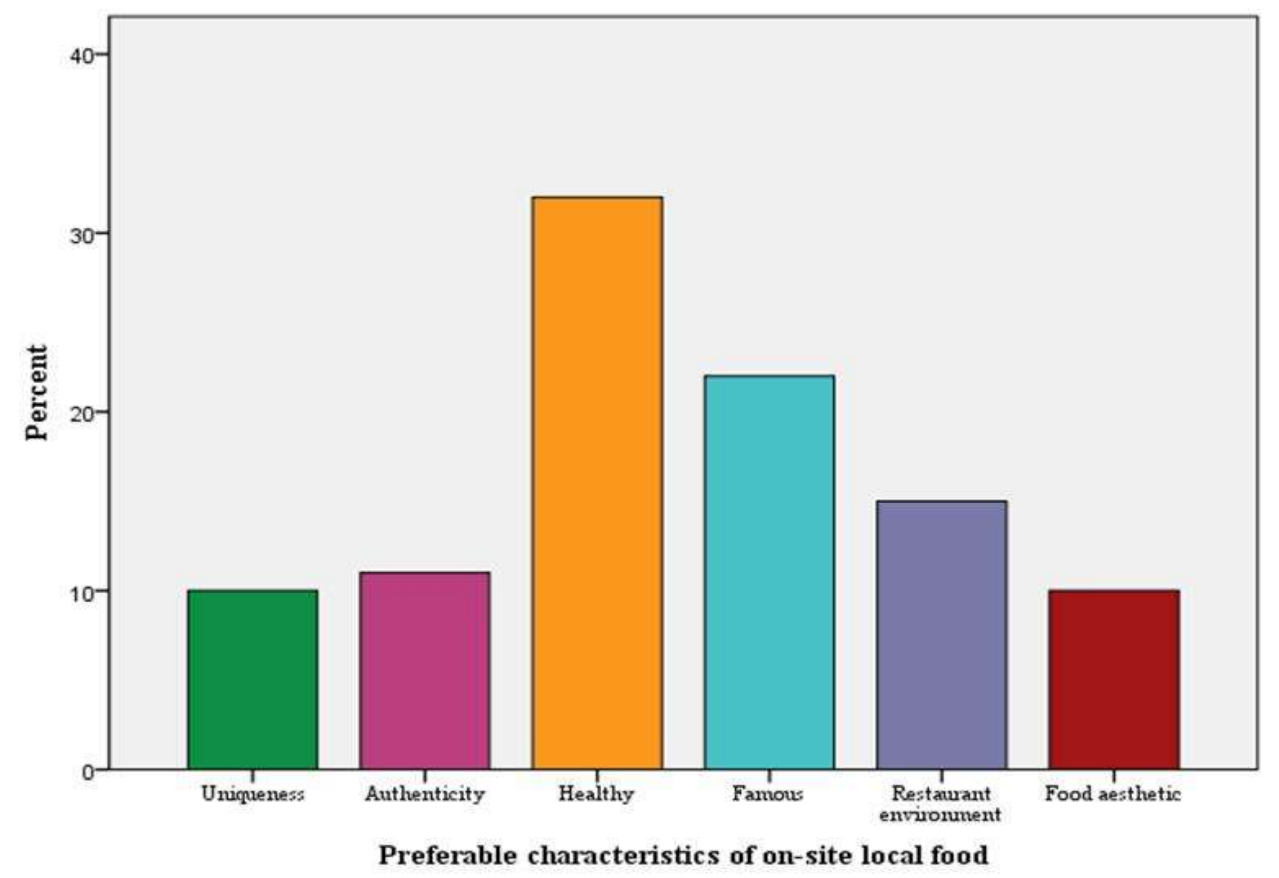

\section{Discussion and implications}

This study examines the relative importance of food in tourism in the context of domestic tourists in Bangladesh. According to tourism literature, it has been suggested that socio-demographic factor can influence tourists' food consumption (Furst et al., 1996; Khan \& Hackler, 1981; Mak et al., 2012; Randall \& Sanjur, 1981). In this study, the gender distribution is justly equable with a higher frequency in the male group which is $61 \%$ of the total population shown in Table 1. According to the demographic profile see in Table 1, it can be said that the participants in this study are young and well educated which is mostly similar of the previous study of food tourism (Chen \& Huang, 2016; Kim et al., 2011; McKercher et al., 2008). According to Table 2 to it has found that male participants are mostly attracted by food to travel in a destination in comparing with female participants. These findings disagree with the previous findings of Chen \& Huang (2016) who showed that women put more importance on food than men to travel to a destination. The reason for this dissimilarity of findings may be that in Bangladesh males are more outgoing in nature and they also get more freedom to visit different destination than females. That is why, in this study, male participants feel more interested to participate than the female participants.

An association was found between the food as a motivator to travel and education shown in Table 2. Specifically, undergraduates consider food as a motivator to travel higher than postgraduates. Here one of the reasons that can be obvious that, as the undergraduates are younger than the postgraduates, they may feel more interested to taste different exotic food in a destination which motivates them to travel. Besides comparing with the older people, young people are more energetic to explore adventurous destinations so that they get more chances to taste different local food. Along with the raise of age older people lose taste and do not feel much interested to explore food unknown to them. In the previous food tourism research, it has also been shown that older people show different food choice due to changes in sensitivity compared to the younger one (Khan \& Hackler, 1981). Tse \& Crotts (2005) have found that the number and age range of food explorations are negatively correlated with tourists' age. According to Mak et al. (2012), senior tourists may take a confined range of foods obtainable in a tourism destination. 
This study found that tourist can be motivated by local food to travel to a national destination. This has been identified by the respondents of the survey who choose local food as one of the important purposes of travelling comparing with other purposes (see Figure 2). It is mostly similar with the previous study of food tourism where researchers found that local food can motivate tourist to visit a destination and it also helps to promote the uniqueness of a destination (Chen \& Huang, 2016; Kivela \& Crotts, 2006; Okumus et al., 2013). Among different categories of tourists shown in Figure 3, the highest number of tourists agreed that to visit a domestic destination local food influence their decision. As they are the most frequent traveler in nature, destination marketing managers can target these tourists and give more importance to local food to promote a domestic destination. Björk \& Kauppinen-Räisänen (2016) have suggested that, for promotional activities and local development, service providers, destinations, countries or regions can utilize local food as a tourism resource.

In this study, some criteria have been used shown in Figure 4 to identify domestic tourist requirement to select local food in a destination. Most of the respondents of this study survey were concern about the healthiness of local food because they think healthy food give much satisfaction and unhealthy food demotivate them to consume that food. These findings agree with Chen \& Huang (2016) and Pearson et al. (2011) who also showed that the healthiness of local food plays a role as an internal motivator which can motivate tourists to visit a destination. Respondents also prefer famous food and restaurant environment as an important criterion to consume local food. In the previous study, it has been shown that tourists stay in a destination for the purpose of consuming delicious food in a friendly and nice environment (Hjalager \& Corigliano, 2000). Besides the respondents also concern about the authenticity of local food as most of the tourist want to experience the genuine taste of the iconic dishes of a destination. According to Özdemir \& Seyitoğlu (2017), in order to develop positive attitude towards food as well as restaurant environment, it must be authentic so that this authenticity leads tourist to revisit in a particular destination and repurchase from particular restaurants.

The research can be used for some practical implication. It will help the destination marketing organizations (DMOs) to develop long term strategy for tourism in a particular destination. Destination manager can accurately identify the importance of food tourism which will help them to focus on food to attract the potential tourist. As Bangladesh is blessed with both natural beauty and various famous iconic dishes, food tourism can be an attractive purpose along with sightseeing activities. The hospitality industry can also be benefited from the findings of this study. They can target a specific segment to attract them according to their preference. For example, they can take a clue from Hong Kong where the growing number of restaurant offering varieties of cuisines is the main reason for the increasing number of tourist arrivals (Ab Karim \& Chi, 2010). They can also develop food quality and service system according to tourists' preferable criteria. Overall this study will be useful for developing food tourism in Bangladesh which in turn promote destination uniqueness and motivate potential tourist to visit domestic destination.

\section{Concluding remarks}

The main objective of this research presented in this paper is to address the importance of food tourism in Bangladesh in the context of Domestic tourists. By applying quantitative techniques on selected sample data, this study addresses the research objective. The findings coming from this study show that the importance of food in tourism varies from tourist to tourist and food motivates the domestic tourist to visit a destination differently which varies according to the tourist demographic profile. Particularly, it is pointed out that the male and young tourists perceive food as an important motivator to travel to different tourist destinations in Bangladesh. Besides, it is found that the domestic tourists visit Bangladesh not only for sightseeing but also for tasting local food of a destination. This study has also indicated that a large number of domestic tourists who are frequent traveler have agreed that local food motivates them to visit a destination. According to the research findings, it can be articulated that there is a great potentiality of developing food tourism in Bangladesh. Highlighting the importance of food in tourism functions might be a prominent way of upholding and uplifting domestic tourism in different current and potential destinations.

Although this study attempts to identify the relative importance of food tourism, it has some limitations. Firstly, 
this study is conducted at a limited scale in terms of the sample size. A large sample might offer more insights into the association between demographic variables and food tourism. Secondly, this study faces some problems while collecting information through online survey as the respondents did not get any chances to ask questions about this survey. Incorporating reasonable number of face-to-face interview along with the online and on-site survey might be useful to address the inner perceptions of tourist regarding local food of domestic destinations. Despite the shortcomings related to sampling, this study indicates some potentiality for further research. Future researchers can explore the insights of food tourism in Bangladesh with a large sample. It also needs to look at how demographic characteristics of tourists influence the purchase behavior in relation to food tourism. Furthermore, this research suggests utilizations of a mix method approach to reveal the current research problem. A comparative study between domestic and international tourists regarding the views and preferences of food tourism might be useful to the food tourism businesses.

\section{References}

Ab Karim, S., \& Chi, C. G.-Q. (2010). Culinary Tourism as a Destination Attraction: An Empirical Examination of Destinations' Food Image. Journal of Hospitality Marketing \& Management, 19(6), 531-555. https://doi.org/10.1080/19368623.2010.493064

Barthes, R. (2012, December 7). Toward a Psychosociology of Contemporary Food Consumption. Food and Culture; Routledge. https://doi.org/10.4324/9780203079751-10

Beer, S. (2008). Authenticity and food experience - commercial and academic perspectives*. Journal of Foodservice, 19(3), 153-163. https://doi.org/10.1111/j.1745-4506.2008.00096.x

Björk, P., \& Kauppinen-Räisänen, H. (2016). Local food: A source for destination attraction. International Journal of Contemporary Hospitality Management, 28(1), 177-194. https://doi.org/10.1108/IJCHM-05-20140214

Boniface, P. (2017). Tasting Tourism: Travelling for Food and Drink. Routledge. https://doi.org/10.4324/9781315241777

Chang, R. C. Y., Kivela, J., \& Mak, A. H. N. (2010). Food preferences of Chinese tourists. Annals of Tourism Research, 37(4), 989-1011. https://doi.org/10.1016/j.annals.2010.03.007

Chang, R. C. Y., Kivela, J., \& Mak, A. H. N. (2011). Attributes that influence the evaluation of travel dining experience: When East meets West. Tourism Management, 32(2), 307-316.

Chen, Q., \& Huang, R. (2016). Understanding the importance of food tourism to Chongqing, China. Journal of Vacation Marketing, 22(1), 42-54. https://doi.org/10.1177/1356766715589427

Cohen, E., \& Avieli, N. (2004). Food in tourism. Annals of Tourism Research, 31(4), 755-778.

Corigliano, M. A. (2003, August 27). The route to quality: Italian gastronomy networks in operation. Tourism and Gastronomy; Routledge. https://doi.org/10.4324/9780203218617-17

Fox, R. (2007). Reinventing the gastronomic identity of Croatian tourist destinations. International Journal of Hospitality Management, 26(3), 546-559. https://doi.org/10.1016/j.ijhm.2006.03.001

Frochot, I. (2003). An Analysis of Regional Positioning and Its Associated Food Images in French Tourism Regional Brochures. Journal of Travel \& Tourism Marketing, 14, 77-96. https://doi.org/10.1300/J073v14n03_05

Furst, T., Connors, M., Bisogni, C. A., Sobal, J., \& Falk, L. W. (1996). Food Choice: A Conceptual Model of the Process. Appetite, 26(3), 247-266. https://doi.org/10.1006/appe.1996.0019

Grbac, B., \& Milohanović, A. (2008). Contribution of food products in creating cultural identity of tourist destination. Proceedings of the WSEAS International conference on Cultural heritage and tourism - New aspects of Cultural heritage and tourism, 83.

Hall, C. M., Sharples, L., Mitchell, R., Macionis, N., \& Cambourne, B. (2004). Food Tourism Around The World. Routledge.

Hjalager, A.-M., \& Corigliano, M. A. (2000). Food for tourists-Determinants of an image. International Journal of Tourism Research, 2(4), 281-293. https://doi.org/10.1002/1522-1970(200007/08)2:4<281::AIDJTR228>3.0.CO;2-Y

Hjalager, A.-M., \& Richards, G. (2003). Tourism and Gastronomy. Routledge.

Ignatov, E., \& Smith, S. (2006). Segmenting Canadian Culinary Tourists. Current Issues in Tourism, 9(3), 235255. https://doi.org/10.2167/cit/229.0

Jacobsen, J. K. S., \& Haukeland, J. V. (2002). A Lunch with a View: Motor Tourists' Choices and Assessments of Eating-places. Scandinavian Journal of Hospitality and Tourism, 2(1), 4-16. https://doi.org/10.1080/150222502760347509

Jang, S. (Shawn), Ha, J., \& Park, K. (2012). Effects of ethnic authenticity: Investigating Korean restaurant customers in the U.S. International Journal of Hospitality Management, 31(3), 990-1003. 
https://doi.org/10.1016/j.ijhm.2011.12.003

Jones, A., Jenkins, I., \& Jenkins, I. (2003, August 27). 'A Taste of Wales - Blas Ar Gymru': Institutional malaise in promoting Welsh food tourism products. Tourism and Gastronomy. https://doi.org/10.4324/9780203218617-14

Khan, M. A., \& Hackler, L. R. (1981). Evaluation of food selection patterns and preferences. C R C Critical Reviews in Food Science and Nutrition, 15(2), 129-153. https://doi.org/10.1080/10408398109527314

Kim, Y. G., Eves, A., \& Scarles, C. (2009). Building a Model of Local Food Consumption on Trips and Holidays: A Grounded Theory Approach. International Journal of Hospitality Management, 28, 423-431. https://doi.org/10.1016/j.ijhm.2008.11.005

Kim, Y. H., Goh, B. K., \& Yuan, J. (Jessica). (2010). Development of a Multi-Dimensional Scale for Measuring Food Tourist Motivations. Journal of Quality Assurance in Hospitality \& Tourism, 11(1), 56-71. https://doi.org/10.1080/15280080903520568

Kivela, J., \& Crotts, J. C. (2006). Tourism and Gastronomy: Gastronomy’s Influence on How Tourists Experience a Destination. Journal of Hospitality \& Tourism Research, 30(3), 354-377. https://doi.org/10.1177/1096348006286797

Lin, Y.-C., Pearson, T. E., \& Cai, L. A. (2011). Food as a form of destination identity: A tourism destination brand perspective. Tourism and Hospitality Research, 11(1), 30-48. https://doi.org/10.1057/thr.2010.22

Logue, A. W. (1991). The psychology of eating and drinking: An introduction, 2nd ed (pp. xiii, 377). W H Freeman/Times Books/ Henry Holt \& Co.

Long, L. M. (2013). Culinary Tourism. In P. B. Thompson \& D. M. Kaplan (Eds.), Encyclopedia of Food and Agricultural Ethics (pp. 1-8). Springer Netherlands. https://doi.org/10.1007/978-94-007-6167-4_416-1

Mak, A. H. N., Lumbers, M., Eves, A., \& Chang, R. C. Y. (2012a). Factors influencing tourist food consumption. International Journal of Hospitality Management, 31(3), $928-936$. https://doi.org/10.1016/j.ijhm.2011.10.012

Mak, A. H. N., Lumbers, M., Eves, A., \& Chang, R. C. Y. (2012b). Factors influencing tourist food consumption. International Journal of Hospitality Management, 31(3), 928-936. https://doi.org/10.1016/j.ijhm.2011.10.012

McKercher, B., Okumus, F., \& Okumus, B. (2008, October 12). (PDF) Food Tourism as a Viable Market Segment: It's All How You Cook the Numbers! ResearchGate. https://doi.org/10.1080/10548400802402404

Mitchell, R., Hall, C. M., \& Hall, C. M. (2004, February 18). Consuming tourists: Food tourism consumer behaviour. Food Tourism Around The World. https://doi.org/10.4324/9780080477862-11

Morris, J. (2015, October 1). Food Tourism Is the Focus of Many Destination Marketing Organizations |.TR [Https://www.tourism-review.com/]. /Travel-Tourism-Magazine-Food-Tourism-Is-the-Focus-of-ManyDestination-Marketing-Organizations-Article2635. https://www.tourism-review.com/travel-tourismmagazine-food-tourism-is-the-focus-of-many-destination-marketing-organizations-article2635

Okumus, F., Kock, G., Scantlebury, M. M. G., \& Okumus, B. (2013). Using Local Cuisines when Promoting Small Caribbean Island Destinations. Journal of Travel \& Tourism Marketing, 30(4), 410-429. https://doi.org/10.1080/10548408.2013.784161

Özdemir, B., \& Seyitoğlu, F. (2017). A conceptual study of gastronomical quests of tourists: Authenticity or safety and comfort? Tourism Management Perspectives, 23, 1-7. https://doi.org/10.1016/j.tmp.2017.03.010

Packard, D. P., \& McWILLIAMS, M. (1993). Cultural Foods Heritage of Middle Eastern Immigrants. Nutrition Today, 28(3), 6-12.

Pearson, D., Henryks, J., Trott, A., Jones, P., Parker, G., Dumaresq, D., \& Dyball, R. (2011). Local food: Understanding consumer motivations in innovative retail formats. https://doi.org/10.1108/00070701111148414

Prescott, J., Young, O., O’Neill, L., Yau, N. J. N., \& Stevens, R. (2002). Motives for food choice: A comparison of consumers from Japan, Taiwan, Malaysia and New Zealand. Food Quality and Preference, 13(7), 489495. https://doi.org/10.1016/S0950-3293(02)00010-1

Pullphothong, L., \& Sopha, C. (2019). GASTRONOMIC TOURISM IN AYUTTHAYA, THAILAND. 6.

Quan, S., \& Wang, N. (2003). Towards a structural model of the tourist experience: An illustration from food experiences in tourism. Tourism Management, 25(3), 297-305.

Randall, E., \& Sanjur, D. (1981). Food preferences-Their conceptualization and relationship to consumption. Ecology of Food and Nutrition, 11(3), 151-161. https://doi.org/10.1080/03670244.1981.9990671

RIMMINGTON, M., \& YÜKSEL, A. (1998). Tourist Satisfaction and Food Service Experience: Results and Implications of an Empirical Investigation. Anatolia, 9(1), 37-57. https://doi.org/10.1080/13032917.1998.9686958

Symons, M. (1999). Gastronomic authenticity and sense of place. /paper/Gastronomic-authenticity-and-sense-ofplace-Symons/039f87e579df09d6ff191d73cb91ca40c4e041b7

Tse, P., \& Crotts, J. (2005). Antecedents of novelty seeking: International visitors' propensity to experiment across 
Hong Kong's culinary traditions. Tourism Management - TOURISM MANAGE, 26, 965-968. https://doi.org/10.1016/j.tourman.2004.07.002

Updhyay, Y., \& Sharma, D. (2014). Culinary preferences of foreign tourists in India. Journal of Vacation Marketing, 20(1), 29-39. https://doi.org/10.1177/1356766713486143 